\title{
A História Oral de Vida como método desestabilizador nas pesquisas sobre sexualidade e gênero
}

\author{
Alexandre Ceconello Marinho ${ }^{1}$ \\ Universidade de São Paulo
}

Resumo: Com base em uma experiência de pesquisa com pessoas transexuais que toma o método da História Oral - mais especificamente um ramo seu, a História Oral de Vida - como base do trabalho, este artigo foi produzido na intenção de refletir acerca do uso de fontes orais em pesquisas acadêmicas, principalmente as que tratam sobre sexualidade e gênero. Além disso, apresenta a História Oral como uma alternativa aos métodos que objetificam entrevistados e fragmentam narrativas, expropriando seu sentido, a fim de confirmarem hipóteses preestabelecidas.

Palavras-chave: história oral; transexualidade; sexualidade; gênero; metodologia.

\footnotetext{
${ }^{1}$ Doutorando em Psicologia Social pela Universidade de São Paulo (USP), Mestre em Educação pela Universidade Estadual de Campinas (UNICAMP), com Especialização em Saúde da Família pela Universidade Federal de São Paulo (UNIFESP) e Graduação em Psicologia pela Universidade Metodista de Piracicaba (UNIMEP). Tem experiência em atendimento individual e grupal; supervisão clínico-institucional para profissionais e equipes; gestão de serviços e políticas públicas, principalmente nas áreas de Saúde e Assistência Social; e docência no ensino superior. Por isso, tem pesquisado e atuado principalmente nos seguintes temas: psicologia social, políticas públicas; saúde mental; vulnerabilidade social; direitos humanos e sociais; sexualidades; pós-estruturalismo; e abordagens fenomenológica, existencial e humanista.
} 


\title{
Oral Life History as a destabilizing method in research on sexuality and gender
}

\begin{abstract}
Based on research with transexuals that uses the Oral History method more specifically one branch of it, the Oral Life History - as the basis of the work, this article was produced with the intention of reflecting on the use of oral sources in academic research, especially those dealing with sexuality and gender. In addition, it presents Oral History as an alternative to methods that treat people as objects and fragment the narratives, expropriating their meaning, in order to confirm preestablished hypotheses.
\end{abstract}

Keywords: oral history; transexuality; sexuality; gender; methodology.

\section{La Historia de Vida Oral como método desestabilizador en la investigación sobre sexualidad y género}

\begin{abstract}
Resumen: Partiendo de una experiencia de investigación con personas transexuales que utiliza el método de Historia Oral - más específicamente una rama suya, la Historia de Vida Oral - como base del trabajo, este artículo fue elaborado con la intención de reflexionar sobre el uso de fuentes orales en investigación académica, especialmente las que se ocupan de la sexualidad y el género. Además, presenta la Historia Oral como una alternativa a los métodos que tratan a las personas como objetos y fragmentan narrativas, expropiando su significado, con el fin de confirmar hipótesis preestablecidas.
\end{abstract}

Palabras clave: historia oral; transexualidad; sexualidad; género; metodología. 
$\mathrm{C}$ erta vez, em uma rede social, li a crítica de uma travesti afirmando que a partir daquele momento cobraria para fornecer entrevistas a pesquisadores. Ela se dizia cansada de contar sua história, falar de seus pontos de vista e quase nunca receber um retorno sobre os conteúdos fornecidos. Não sabia "para que" e "no que" havia resultado o uso de suas narrativas. Das poucas vezes que recebeu uma devolutiva, não concordou e/ou tampouco compreendeu a análiseinterpretação realizada pelo pesquisador. Parecia sentir-se expropriada no sentido de suas palavras.

Essa forma de lidar com narrativas em uma relação de pesquisa, que produz uma espécie de sentido aviltado, não parece ser um fato isolado, uma fatalidade associada a um risco. Ocorre que grande parte das metodologias de pesquisa que utilizam fontes orais possibilita o recorte de relatos para servirem aos objetivos fixados. E, às vezes, a utilização de entrevistas serve apenas para confirmar hipóteses preestabelecidas. Queiroz (1983: 93-94), ao discorrer sobre o uso de dados colhidos por fontes orais, afirma que este pode ser um dos caminhos escolhidos pelo pesquisador: procurar informações que lhe interessam e respondam aos objetivos da pesquisa, decompondo em partes o texto produzido pela narrativa da pessoa entrevistada. A autora, no entanto, sugere que essa fragmentação obedeça, "tanto quanto possível, às relações existentes entre as partes". Mas, fica a questão: até que ponto é possível manter a fidelidade dos fragmentos ao sentido geral de uma narrativa integral?

Sabemos que o advento do positivismo, no século XIX, transformou a relação da sociedade com o ato do conhecimento, promovendo um cientificismo baseado na busca por leis naturais, verdadeiras e universais. Em sua radicalidade, a ideologia positivista considera as coisas e as pessoas estudadas como meros objetos e eleva o pesquisador à posição de detentor de um método que poderá revelar verdades absolutas. Esse modo de produzir conhecimento é, ainda hoje, dominante nas organizações e estabelecimentos que ensinam e fazem pesquisa.

Conforme Benelli (2019: 90), a universidade geralmente ensina fazer "um tipo de pesquisa de corte positivista tradicional” e, nesta modalidade,

o cientista é um especialista autorizado e detentor de um saber-poder a partir do qual
se intromete de modo autoritário, supostamente neutro e técnico, imparcial e objetivo,
sobre um objeto, com a finalidade de conhecê-lo, para saber como funciona, visando
modificá-lo de acordo com seu saber científico verdadeiro. Há uma subordinação ob-
jetificadora e coisificante do outro, o sujeito da pesquisa é reduzido a um objeto, nor-
malmente um objeto passivo. (BENELLI, 2019: 92)

Mas, apesar dessa tradição ainda ser dominante, muitos métodos têm surgido abrindo fissuras no terreno plano do positivismo. A História Oral, por exemplo, percorre na contramão dessa via: é crítica ao modo positivista tradicional e à objetificação e submissão do outro ao saber do cientista. Como veremos adiante, quem narra a história deve ser considerado colaborador e não sujeito passivo na pesquisa. Segundo Portelli (2010: 7), o pesquisador precisa funcionar como mediador, uma espécie de canal, para que as palavras do colaborador cheguem a um espaço mais amplo e/ou diferente daquele que lhe é de costume. Por isso, Meihy (2005: 148) confirma o papel principal e primordial do narrador e alerta: demandará, no âmbito da pesquisa, a maior e mais importante responsabilidade do oralista ${ }^{2}$. 
Mobilizado por estas e outras questões que envolvem o cuidado com as narrativas de sujeitos que disponibilizam suas histórias, sobretudo daqueles que estão em situação de vulnerabilidade e socialmente marginalizados, este artigo aconteceu após a realização de uma pesquisa produzida pelo método da História Oral - mais especificamente um ramo seu, a História Oral de Vida - com pessoas transexuais ${ }^{3}$.

Por isso, busco disparar algumas reflexões sobre o tema, a fim de produzir novas questões e também contribuir com discussões existentes, tendo em vista o diálogo com outras(os) autoras(es) aqui referenciadas(os).

\section{O uso de fontes orais}

O advento da escrita é a marca inaugural do chamado período histórico, quando as sociedades letradas passaram a registrar o presente escrevendo o passado. Não restam dúvidas de que essa invenção operou uma das mais profundas transformações nas formas de vida coletiva, tornando-se - a escrita - o principal instrumento para regulação das ações e atividades humanas.

No entanto, há outro elemento a ser considerado: é na oralidade que se encontra a mais antiga forma de comunicação entre os seres humanos na passagem das tradições e produção histórica. Mesmo após o advento da escrita, de acordo com Garrido (1993: 34), até o século XVIII "os testemunhos orais gozaram de um reconhecido prestígio que desapareceria com o desenvolvimento da história acadêmica profissional que se produziu durante o século XIX”.

A história enquanto arte de retórica, que não possuía um referencial normativo visando padronizar o seu fazer, com a influência do iluminismo e do positivismo, passou a ter regramentos rígidos para sua consideração como ciência. Dessa forma, a oralidade foi contida pelas normas que determinam o ato de produzir História na perspectiva da ciência moderna (GARRIDO, 1993: 45-7).

A invenção do gravador portátil na modalidade de fita magnética e sua posterior difusão e comercialização inicialmente na Europa e nas Américas do Norte e Central, a partir da década de 1950, foi um divisor de águas para as pesquisas nutridas por narrativas. Com a possibilidade de circular com o aparelho em diferentes lugares, gravando e reproduzindo as vozes registradas inúmeras vezes, historiadoras(es), sociólogas(os), antropólogas(os), psicólogas(os), dentre outras(os) profissionais e pesquisadoras(es) das áreas de ciências humanas e sociais, apropriaram-se desse instrumento para coletar dados de fontes orais e, ao lado de outros documentos, como imagens fotográficas e registros escritos, produzirem conhecimentos e (re)construírem histórias. (ALBERTI, 2005)

No Brasil, a introdução da prática em história oral aconteceu nos anos de 1970, auge da ditadura militar no país. Mas, segundo Ferreira e Amado (2006), é a partir dos anos de 1990 que ela se expande de maneira mais significativa em organizações e estabelecimentos acadêmicos, tendo em vista: a multiplicação de seminários sobre o tema; a incorporação da técnica/método em programas de pós-graduação; e a articulação de pesquisadores nacionais com oralistas e programas de pesquisa estrangeiros de reconhecimento internacional.

Ainda que inicialmente houvesse uma concepção limitada à coleta de dados, a História Oral deu seus primeiros passos para se constituir uma metodologia

3 Trata-se da pesquisa que resultou na dissertação intitulada Histórias Trans-Criadas: cuidado de si nas formas de (re)existir (MARINHO, 2018), apresentada à Faculdade de Educação (FE) da Universidade Estadual de Campinas (UNICAMP), para a obtenção do título de mestre, e aprovada pelo Comitê de Ética em Pesquisa (CEP) da UNICAMP, através do parecer $\mathrm{n}^{0}$ 2.033.748 e CAAE 66953717.3.0000.5404. 
investida de potência fora e dentro do Brasil. Meihy e Holanda (2013; 98-105) explicam que, nesse universo onde o código escrito goza de status oficial, trabalhar com história oral se tornou um grande desafio justamente pelas divergências acerca do seu lugar nas pesquisas. Ferreira e Amado (2006) analisaram como pesquisadores que trabalham com história oral consideram-na, identificando três principais formas: como técnica; como disciplina; e como metodologia.

Alguns autores, como William Roger (1986), entendem a história oral como um mero procedimento técnico de registro de entrevistas para uso como fonte de dados complementar a outros documentos. Geralmente, documentos escritos. Essa posição, que pode ser considerada a mais conservadora e limitada, é sustentada pela ideia de que a história oral carece de fundamentos filosóficos e conceituais que possam determiná-la como disciplina ou, até mesmo, metodologia. Os pesquisadores que trabalham nessa linha estão preocupados especificamente com a dimensão técnica das gravações, como o tipo de aparelhagem utilizada, o ato das transcrições e a guarda e conservação das entrevistas (FERREIRA e AMADO, 2006: XII).

$\mathrm{Na}$ perspectiva daqueles que consideram a história oral uma disciplina, importa-lhes não apenas as técnicas específicas de pesquisa, mas, também, os procedimentos considerados singulares e um conjunto próprio de conceitos. No entanto, é justamente no corpo teórico-conceitual que as contradições aparecem: bastante complexos e difusos, com alguns até contraditórios entre si. Outro problema no intento de torná-la uma disciplina consiste no risco de engessamento técnico-teórico e na sua limitação prática (FERREIRA e AMADO, 2006: XIIXIII).

Portanto, é enquanto metodologia que a história oral encontra maior aceitação entre os pesquisadores. Assim, não lhe cabe apenas cumprir uma função técnica ou procedimental, isentando-a de fundamentos; é considerada uma ponte entre a prática e a teoria, por isso não oferece respostas ou interpretações. Ela suscita questões! A teoria é complementar à História Oral e pode ser oriunda da filosofia, das ciências sociais, da antropologia, da psicologia etc. (FERREIRA e AMADO, 2006: XII-XIV).

\section{A História Oral de Vida}

Apesar da coexistência de diferentes linhas e grupos de pesquisa sobre História Oral e das múltiplas possibilidades de se trabalhar com o método, minha pesquisa foi influenciada pelas experiências e orientações de autoras(es) vinculadas(os) ao Núcleo de Estudos em História Oral (NEHO), da Universidade de São Paulo (USP), como Meihy e Holanda (2013), Caldas (1999a; 1999b) e Guimarães (2011). Esta escolha teve como base dois aspectos principais: o da colaboração, possibilitando a intervenção do entrevistado na fase chamada de transcriação; e o da inclusão das narrativas em sua integralidade por considerá-las o elemento fundamental da pesquisa.

Meihy e Holanda (2013) apontam que a pesquisa em História Oral tem como marca e elemento fundante a subjetividade. Utilizada na realização da pesquisa que originou este artigo, uma de suas modalidades, a História Oral de Vida, consiste em entrevistas não estruturadas e livres de questionários preestabelecidos: trata-se "da narrativa da experiência de vida de uma pessoa" (MEIHY, 2005: 147) que é gravada por equipamentos eletrônicos, transcrita, textualizada e transcriada.

Para Guimarães (2011: 22), que realizou uma pesquisa com jovens militantes 
da cidade de Campinas, é através de entrevistas livres, sem perguntas indutivas, o ponto de partida da História Oral de Vida enquanto metodologia de pesquisa.

Pela exigência de ocorrer o mais livremente possível, as entrevistas geralmente são longas, constituindo histórias de acordo com a vontade e as condições de cada colaborador. Essa forma de se fazer facilita compreender os sentidos das experiências vividas pelos entrevistados em suas contradições, fantasias, afirmações e desejos. (MEIHY, 1994: 4)

No decorrer do processo de elaboração da pesquisa que originou este artigo, a escolha por apenas dois colaboradores foi considerada suficiente para que as narrativas pudessem ser mais bem exploradas e seus objetivos atingidos. Ou seja: uma vez que a atenção esteve voltada para as versões singulares dos acontecimentos, foi na subjetividade - no modo como cada sujeito apreendeu determinadas questões e que em determinado momento contou sobre elas - que se garantiu "às narrativas decorrentes da memória um corpo original e diverso dos documentos convencionais", produzindo um sentido diferente de "qualquer matéria que se classifique nos rigores dos métodos probatórios absolutos" (MEIHY e HOLANDA, 2013: 34).

A pesquisa em História Oral não tem finalidade comprobatória - talvez sua posição mais definitiva seja afirmar a inexistência de verdades absolutas - , mas requer certo rigor ético quanto ao processo e demanda planejamento. Meihy e Holanda (2013: 29) destacam que a iniciativa planejada é ponto de partida para qualquer projeto de pesquisa e ponderam: "como empreendimento de trabalho que implica busca, o projeto é provisório". Além disso, a busca pela espontaneidade no momento narrativo não abstém o pesquisador e sua pesquisa de intencionalidade: a entrevista só ocorre porque há um projeto com um tema que dá sentido à sua ocorrência.

Considerando, portanto, que a trajetória dos sujeitos é inevitavelmente marcada por processos culturais e históricos, a interlocução com o pesquisador é fundamental para a compreensão da relação cultura-subjetividade presente na narrativa, sempre à luz do tema mobilizador.

Guimarães (2011: 22-23), citando Leite (2008: 71-2), explica que "toda entrevista de História Oral de Vida é recortada por um ou mais temas específicos trazidos pelo pesquisador, seja através da pergunta de corte, como propõe Meihy, seja pela própria definição das etapas do projeto". Meihy e Holanda (2013, p. 29) apresentam as seis principais etapas para realização da pesquisa em História Oral:

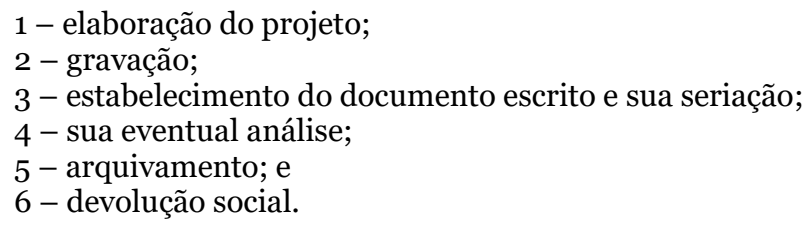

Todas as etapas são importantes e exigem rigor ético do pesquisador. No entanto, as etapas 3 e 4 são as que mais demandam sensibilidade do oralista por contemplar a passagem do oral para o escrito, aumentando a influência do pesquisador sobre as narrativas. Nestas etapas, Meihy (2005: 195-203) orienta que o pesquisador faça três processos básicos para o tratamento do material: a transcrição das gravações; a textualização das entrevistas; e a transcriação das narrativas, o que considerei como o momento mais desafiador da pesquisa que originou este artigo.

A transcriação é a última fase dos trabalhos com as entrevistas. Nela, 
buscamos (re)criar em um novo texto a atmosfera do momento narrativo. E isso não é possível de se fazer apenas com a reprodução gráfica de cada uma das palavras. A transcriação é uma fase que requer certa teatralização do que foi contato, buscando levar ao leitor o sentido da narrativa e o conjunto de sensações e emoções vividas no contato entre orador, oralista e o contexto em que se desenvolveu a entrevista. "O fazer do novo texto permite que se pense a entrevista como algo ficcional e, sem constrangimento, se aceita esta condição no lugar de uma cientificidade que seria mais postiça”. (MEIHY, 1991: 30-1)

De acordo com Meihy e Holanda (2013: 137),

\begin{abstract}
depois de exaustivamente trabalhado em todas as suas etapas, até chegar à transcriação, a entrevista deve voltar ao narrador/entrevistado para que ele se reconheça nela, faça durante o ato de conferência a validação que lhe garanta reconhecimento de si mesmo.
\end{abstract}

Uma vez finalizado esse processo, ou seja, tendo as transcriações legitimadas pelos entrevistados após algumas solicitações de alterações estéticas e de inclusão e reorganização de falas, considerei o trabalho concluído. Só então solicitei a assinatura dos colaboradores no Termo de Consentimento Livre e Esclarecido (TCLE) - ou Carta de Autorização e Uso das Entrevistas, conforme proposto por Meihy e Holanda (2013: 148-153) -, momento em que a autorização para utilização e publicação das entrevistas foi oficializada.

Diferente do que ocorre na maioria das pesquisas que utilizam fontes orais, em que a assinatura no TCLE ocorre antes da finalização do tratamento das entrevistas, a assinatura ao final das transcriações ocorreu como forma de garantir não somente a concessão da gravação da entrevista, mas a legitimidade de todo o processo até sua transcriação. Neste documento constou, ainda, a permissão para uso ou não do nome social. Caso a(o) entrevistada(o) preferisse preservar o nome social, foi colocado à disposição o uso de nome fictício, também à escolha da(o) colaboradora(or), o que não ocorreu. Os colaboradores optaram pela manutenção de seus nomes, reforçando a percepção de que eles se reconheceram nas transcriações.

\title{
O tema, a escolha da comunidade de destino e a implicação do pesquisador
}

Medos, assujeitamentos, resistências, sofrimentos e prazeres compõem com outros afetos sentidos que ainda não foram nomeados. Minha memória, em sua singularidade e movimento, traz à tona uma inquietação constante com o corpo, um olhar duvidoso para a pele, no formato e movimento do braço, das pernas, do quadril, no olhar para o espelho, em busca das marcas que imprimem o gênero, das características necessárias à masculinidade tão requisitada por aqueles que apontavam seu distanciamento.

A apresentação deste pequeno fragmento performatiza algo da minha própria história e aparece para sustentar a ideia de que não há neutralidade e tampouco um distanciamento capaz de promover a isenção do pesquisador na relação com quem e com aquilo que se pesquisa. Refiro-me à implicação que nos coloca no campo e em campo.

A implicação não tem a ver simplesmente com engajamento, motivação ou comprometimento com a pesquisa e os colaboradores. É claro que esses elementos são também fundamentais e contribuem para uma boa experiência. Mas, a implicação está para além disso: diz respeito às "instituições que nos 
atravessam"4 (ROMAGNOLI, 2014: 47).

$\mathrm{O}$ meu interesse em contribuir acadêmica e profissionalmente com as necessidades da população LGBTQIA +5 apareceu durante a graduação, a partir do contato com as ideias de pensadores considerados pós-estruturalistas, como Michel Foucault, Gilles Deleuze e Félix Guattari. Mas, foi no exercício da profissão que se consolidou a proposta de pesquisar histórias de mulheres e homens transexuais.

Logo após a graduação, ingressei no serviço público como psicólogo e atuei em diferentes dispositivos do Sistema Único de Saúde (SUS) de uma cidade de médio porte do interior do Estado de São Paulo. Eventualmente, as demandas de atenção e acompanhamento às especificidades de usuárias(os) LGBTQIA+ apareciam em Unidades Básicas de Saúde (UBS) e em serviços de Saúde Mental, como os Centros de Atenção Psicossocial (CAPS). No entanto, foi no Centro de Testagem e Aconselhamento (CTA), que organizava o programa de IST/AIDS 6 do município, o lugar em que tive contato cotidiano com as demandas desse público, principalmente das travestis e das mulheres e homens transexuais que buscavam, direta ou indiretamente, assistência ao processo transexualizador7. Minha percepção sobre o acesso desta população às políticas públicas ultrapassava os muros daquele estabelecimento: a obrigatoriedade do reconhecimento do nome social através de seu uso em documentos oficiais, como em prontuários, atestados e cartões, e ao dirigir-se verbalmente às pessoas travestis e transexuais, por exemplo, era desconhecida pela maioria dos profissionais e gestores da época.

Os CTAs, assim como outros serviços responsáveis por programas governamentais de prevenção às IST/AIDS, foram reconhecidos como um dos palcos fundamentais, sobretudo na década de 1990, para articulação dos primeiros grupos de ativismo brasileiro propriamente LGBTQIA+. E, ainda hoje, em muitas cidades brasileiras, estes serviços funcionam como dispositivo articulador na emergência de lutas, como no caso do município em que atuei como psicólogo.

No entanto, é justamente por esse lugar de referência constituído sobre questões LGBTQIA+, que, não raro, os CTAs acabam se tornando um dos poucos serviços - em muitos lugares, os únicos - que oferecem atenção e cuidado a toda uma população marginalizada no campo da saúde. O que é bem problemático quando tratamos de uma rede de serviços de uma política pública, pois reproduz a exclusão que as pessoas travestis e transexuais vivem também em outros campos da vida. Por exemplo: quando demandas de psicoterapia, de hormonização, de aplicação de testes rápidos e aconselhamentos sobre IST/AIDS, dentre outras que poderiam ser iniciadas ou orientadas a partir de outros serviços, são encaminhadas aos CTAs.

Apesar do público travesti e transexual ter conquistado alguns direitos básicos no SUS e em outras políticas públicas, como o uso do nome social e a

\footnotetext{
4 Baremblitt (2002: 25-27; 136) explica que as instituições são "árvores de composições lógicas" e nelas estão contidos os códigos que regulam as atividades humanas e sociais, seja por força de lei ou por convenções culturais. Por exemplo: podemos falar da linguagem, da saúde, da educação, da família, do trabalho humano como instituições que exercem essa função de, através de código e saberes, indicar o que deve e/ou não dever ser, o que pode e/ou não pode fazer. Por isso, a implicação diz respeito ao atravessamento das inúmeras instituições sobre o nosso corpo no contato com as diferentes questões que nos afetam.

5 Sigla que visa representar o conjunto de pessoas que se identificam lésbicas, gays, bissexuais, travestis, transexuais, queers, intersexuais ou utilizam outras formas de identificação não convencionais e/ou preestabelecidas.

6 A sigla IST significa Infecção Sexualmente Transmissível e AIDS é a sigla de Acquired Immunodeficiency Syndrome, que, na tradução do inglês para o português, significa Síndrome da Imunodeficiência Adquirida.

7 O processo transexualizador foi reconhecido no Sistema Único de Saúde (SUS) a partir de duas normativas expedidas pelo Ministério da Saúde (MS): a Portaria GM/MS 1707, de 18/08/2008, e a Portaria SAS/MS 457, de 19/09/2008. Posteriormente, através de uma decisão judicial proferida em 13/07/2013, em favor de uma Ação Civil Pública, o Ministério da Saúde redefiniu e ampliou o Processo Transexualizador no SUS, através da Portaria GM/MS 2803, de 19/11/2013, visando garantir o acesso a todos os procedimentos de saúde necessários à "cirurgia de transgenitalização e à readequação sexual".
} 
cobertura do processo transexualizador instituídos através de portarias e decretos federais, na prática cotidiana eles são muito pouco difundidos e efetivados, dificultando o acesso. Nessa época, houve um investimento por parte do CTA do município em que atuei para que profissionais e gestores dos diversos serviços de saúde pudessem tomar conhecimento das medidas e que o atendimento fosse adequado aos direitos garantidos pela população travesti e transexual.

Por isso, no CTA recebíamos muito mais do que demandas objetivas por atendimentos de saúde, tornando-se também um espaço de convivência, trocas e afetos. Nesse período, rodas de conversas envolvendo as travestis, as pessoas transexuais e diferentes profissionais das redes de saúde, assistência social e educação foram iniciadas no intuito de acolher as demandas específicas desta população e inseri-las nas diferentes políticas públicas.

Quase sempre muito intensos e desestabilizadores, os depoimentos expressavam situações de violência e sofrimento, táticas de resistência e sentidos diversos presentes nos processos de afirmação identitária. Histórias com pouca visibilidade em espaços institucionais que balizam nossa vida cotidiana. Por isso, essa experiência resultou em uma pesquisa acadêmica que pudesse funcionar como mais um instrumento para favorecer a visibilidade dessas vozes, tornando mulheres e homens transexuais a comunidade de destino ${ }^{8}$.

Influenciada pela binaridade masculino-feminino que contém o gênero na formação das identidades sexuais, a pesquisa contou com apenas duas pessoas colaboradoras autoidentificadas: uma mulher transexual e um homem transexual. A adesão de cada um por uma destas identidades foi fundamental para que ocorresse o convite, uma vez que a intenção da pesquisa que originou este artigo foi explorar os processos de subjetivação que deram sentido às suas trajetórias de vida na relação com estas afirmações identitárias.

As entrevistas ocorreram em fevereiro de 2016, em local escolhido pelos colaboradores, a fim de se criar um ambiente agradável e favorecer a espontaneidade dos depoimentos. Yonara, a primeira entrevistada, sugeriu que nos encontrássemos no serviço de saúde onde ocorriam os atendimentos; Heitor, o segundo entrevistado, me recebeu em sua casa. Cada entrevista durou, em média, uma hora e quinze minutos.

\section{A experiência da pesquisa}

Para Caldas (1999b), na pesquisa em História Oral "o processo inteiro é de diálogo e de transcriação”. Por isso, considero que desde a escolha do tema, que não está desvinculada dos afetos do próprio pesquisador, à escolha dos colaboradores e dos locais das entrevistas, ou seja, todos os contatos, procedimentos e relações estabelecidas durante o processo, produziram efeitos no resultado da referida pesquisa.

A escolha de locais para realização das entrevistas talvez seja uma das mais emblemáticas e que ainda demanda maiores elaborações. A experiência de ter realizado uma das entrevistas em meu local de trabalho e a outra na casa do colaborador produziu algumas reflexões acerca da influência dos diferentes ambientes na forma como aconteceram as narrativas.

É importante ressaltar que, antes da ocorrência da pesquisa, o papel social que desempenhei na relação com Yonara e Heitor foi o de psicólogo. E esta

${ }^{8}$ De acordo com Meihy (2005: 53-7), "comunidade de destino é aquilo que identifica pessoas, os motivos, os traços que as reúnem em características afins”, podendo se tratar de uma vila, um grupo religioso, um movimento social, dentre outros. No caso da pesquisa que originou este artigo, a comunidade de destino é a população transexual. 
relação entre um psicólogo de um serviço público de saúde e uma(um) usuária(o) deste mesmo serviço modula, em certa medida, as ações, o modo de falar, as expectativas de si e do outro. Isso foi nitidamente percebido no início da entrevista realizada em meu ambiente de trabalho, com Yonara, como se estivéssemos iniciando mais um atendimento daquele serviço. No entanto, a retomada do motivo daquela entrevista, reapresentando o tema da pesquisa, e a utilização do gravador foram elementos que produziram a diferença no campo.

Inicialmente, percebi que o gravador causou certo desconforto, fazendo com que buscássemos um novo modo de nos comunicarmos. Para iniciar os relatos, a colaboradora sugeriu que lhe fossem dirigidas perguntas. Assim, ao longo da entrevista, as perguntas foram cedendo lugar ao diálogo mais imediato e a uma posição mais afirmativa da entrevistada.

Por outro lado, a segunda entrevista, realizada na casa do colaborador, iniciou com maior tranquilidade. Percebi que o ambiente, mais especificamente um banco no jardim do condomínio em que ele residia, com uma leve brisa e um clima agradável, nos acolheu. O gravador não realizou desconfortos iniciais, como na primeira entrevista, mas a circulação de outras pessoas pelo local, ainda que distantes, por vezes alterava a intensidade da conexão entre pesquisador e colaborador. No aspecto técnico do equipamento, foi possível perceber a diferença na qualidade das gravações, com maior presença de ruídos (vento, veículos, animais e outras vozes ao fundo) que dificultaram o processo de transcrição da entrevista.

A escolha dos lugares é fundamental para que haja uma boa entrevista, mas cada escolha implica também em valorizar e/ou priorizar elementos em detrimento de outros; assim como outros aspectos positivos e negativos só ocorrerão no momento ou depois da entrevista, sem que se possa controlá-los. No caso da pesquisa em questão, as escolhas levaram em consideração inúmeros fatores, dentre eles, a necessidade de um espaço reservado, o conforto, a acessibilidade, mas principalmente a preferência da pessoa entrevistada.

Durante o processo transcriativo das entrevistas, depois de transcritas e textualizadas, circulei por diversas formas de produção textual, sempre atento ao risco de reduzir histórias tão complexas, tão carregadas de afetos, com tantos paradoxos, rupturas e resistências, em simples significados registrados em papel, considerando o poder exercido por uma pesquisa acadêmica; mas, também, sem a pretensão de abarcar toda complexidade da experiência vivida e contada pelos colaboradores, apontando claramente os limites da pesquisa e do pesquisador.

Dessa forma, imerso em um jogo literário, busquei apresentar uma estética textual que permita ao leitor experienciar diferentes sentidos de uma história registrada em palavras, a partir do seu modo de entrada no meu modo de escrita. Ou seja: a dinâmica escolhida pelo leitor poderá provocar diferentes afirmações, quebras, rupturas, reiterações, paradoxos, faltas. Um simulacro da própria condição da linguagem e sobretudo da existência humana. Afinal de contas, uma história pode ser contada e percebida de diversas formas; pode sugerir a reiteração de significados ou pode provocar sentidos diferentes.

No entanto, apesar da possibilidade de criar junto ao (con)texto do entrevistado, o oralista, desde o momento em que recebe a narrativa e nela atua através da transcriação, deve buscar apoio no conteúdo que o próprio sujeito lhe ofereceu, respeitando os sentidos e os afetos daquela história. Afinal, é a versão do colaborador que está em jogo. 


\section{Considerações finais}

O grande desafio proposto pela História Oral é superar o modo tradicional de se fazer pesquisa. Como uma metodologia que questiona a utilização de registros através de depoimentos para confirmar hipóteses predefinidas pelo pesquisador, sua prática sugere o que Caldas (1999b) chamou de "ação criativa". É por isso que a História Oral é considerada uma proposta metodológica potente: nela habita a possibilidade de romper com a (re)produção de respostas que visam universalizar e generalizar, ampliando espaços na academia aos saberes produzidos em sua singularidade, saberes que se produzem nas infinitas experiências.

Mas, isso não quer dizer que a História Oral se ocupa de histórias individuais.

Pelo contrário.

No exercício da pesquisa que originou este artigo, muitas das experiências contatadas pelos colaboradores são transpassadas por histórias coletivas, de outras travestis e mulheres e homens transexuais. Por exemplo: os conflitos oriundos da exigência burocrática de explicitar, em documentos, o nome social e de registro; o sofrimento em decorrência da transgressão à norma e da transfobia; a arte de reexistir em contexto adverso ao corpo trans, mas comum ao corpo cisgênero. São questões que afetam uma "multidão de corpos", como diriam Negri e Hardt (2005: 248); corpos que se cruzam na multidão, que se misturam, que "são como ondas do mar, em perene movimento e em perene e recíproca transformação" (NEGRI e HARDT, 2005: 248).

Mas, ao mesmo tempo, a história de cada um não pode ser contada da mesma forma e, tampouco, reduzida a um elemento da vida humana: a sexualidade e/ou o gênero, neste caso. Como cada um viveu a experiência de "ser" ou "torna-se" trans, as memórias, os afetos e a forma de dizer-se são singulares. Os valores, as crenças, os discursos reiterados, as dobras e fissuras são únicas, porém, não se constituem independentes, mas são produzidas na relação com o social.

Portanto, a narrativa como reconstrução do passado é flexível e os eventos narrados se dão à luz do vivido no presente. Tudo o que envolve e acontece no momento narrativo - o local; quem é o pesquisador e como ele se coloca; os sons; os objetos presentes; as interrupções; como o sujeito se sente naquele momento; e uma infinidade de coisas possíveis - implica no ato de contar. Além disso, a narrativa pode evocar, manifestar identidades e diferenças, confrontar relações de poder.

Na História Oral de Vida, por ser o pesquisador o responsável por tonalizar as experiências, é imprescindível que tanto a escuta quanto o registro das histórias ouvidas mantenham os narradores como personagens centrais de suas vidas contadas. E, apesar de reconhecer a desigualdade entre pesquisador e pesquisado - como bem lembra Larrosa (1996: 478), o fato do discurso ser "resultado de uma fabricação narrativa, isto é, de um conjunto de operações no discurso e com o discurso, essa fabricação não se faz sem violência" -, estive atento em todas as fases da pesquisa, conseguindo dialogar com os colaboradores e participando-os do processo.

Por isso, a posição do oralista é fundamental para a experiência narrativa do colaborador. Em última instância, no anseio de receber um relato, o pesquisador pode transformar o momento da entrevista em uma prática confessional. É aí que reside a diferença da História Oral para o pesquisador que lança mão desse recurso: ela deve ser uma prática libertadora para aquele que narra. Foucault (2006), ao tratar do cuidado de si, sugere uma vida de autoria de si mesmo, entendendo a escrita como uma estratégia prática na constituição de si, constituição 
essa que está ligada a várias tecnologias do cultivo de si.

Enfim, sendo a memória "um suporte para as narrativas de história oral" (MEIHY, 2005: 62), considero que as lembranças dos narradores da pesquisa que deu origem a este artigo se tornaram vivas, tanto porque fazem parte do repertório inscrito no conjunto social das demais memórias, como também são vidas que ao serem narradas confirmam o presente e expõem as circunstâncias de vida que orientam suas histórias. Portanto, os textos transcriados ao resultarem, como pensa Caldas (1999a: 110), de uma "poética da experiência, clamam por uma poética da leitura e por uma poética da interpretação".

Recebido em 31 de janeiro de 2021.

Aprovado em 7 de junho de 2021.

\section{Referências}

ALBERTI, Verena. Manual de História Oral. Rio de Janeiro: FGV, 2005.

AMADO, Janaína; FERREIRA, Marieta de Moraes. Usos e abusos da história oral. Rio de Janeiro: FGV, 2006.

BAREMBLITT, Gregório. Compêndio de Análise Institucional e outras correntes: teoria e prática. Belo Horizonte: Instituto Feliz Guatarri, 2002.

BENELLI, Silvio José. Problematizando a instituição pesquisa na universidade e nas práticas psicológicas: questões epistemológicas e éticas. Rev. Psicol. UNESP, 18 (especial): 88-120, 2019.

CALDAS, Alberto Lins. Oralidade, texto e história: para ler a história oral. São Paulo: Loyola, 1999a.

CALDAS, Alberto Lins. Transcriação em História Oral. NEHO-História, 1 (1): 7179, 1999b.

FOUCAULT, Michel. A hermenêutica do sujeito. São Paulo: Martins Fontes, 2006.

GARRIDO, Joan del Alcázar. As fontes orais na pesquisa histórica: uma contribuição ao debate. ANPUH/Marco Zero, 13 (26): 33-54, 1993.

GUIMARÃES, Áurea M. Vidas de Jovens Militantes. Tese de Livre Docência. Educação, UNICAMP, 2011. Formación. Barcelona: Edital Laertes, 1996. 
LEITE, Tarcísio de Arantes. O dilema da interferência na História Oral: novos problemas e novas respostas. Oralidades: Revista de História Oral, 2 (3): 65-82, 2008.

MARINHO, Alexandre Ceconello. Histórias Trans-Criadas: cuidado de si nas formas de (re)existir. Dissertação de Mestrado. Educação, UNICAMP, 2018.

MEIHY, José Carlos Sebe Bom; HOLANDA, Fabíola. História oral: como fazer, como pensar. São Paulo: Contexto, 2013.

MEIHY, José Carlos Sebe Bom. Manual de História Oral. São Paulo: Loyola, 2005 .

MEIHY, José Carlos Sebe Bom. Definindo História Oral e Memória. Cadernos Ceru, 5 (2): 52-60, 1994.

MEIHY, José Carlos Sebe Bom. Canto de Morte Kaiowá: História Oral de Vida. São Paulo: Loyola, 1991.

NEGRI, Toni; HARDT, Michael. Multidão: guerra e democracia na era do Império. Rio de Janeiro: Record, 2005.

QUEIROZ, Maria Isaura de. Variações sobre a técnica de gravador no registro de informação viva. São Paulo: USP, 1983.

ROGER, William. Notes on history. International Journal of Oral History, 7 (1): 23-8, 1986.

PORTELLI, Alessandro. História oral e poder. Mnemosine, 6 (2): 2-13, 2010.

ROMAGNOLI, R. C. "O conceito de implicação e a pesquisa-intervenção institucionalista”. Psicologia \& Sociedade, 26 (1): 44-52, 2014. 


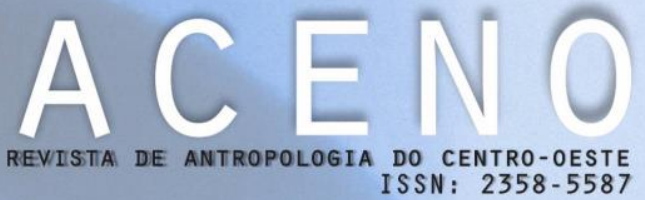

A Aceno - Revista de Antropologia do Centro-Oeste recebe o ano inteiro, em

\section{FLUXO CONTÍNUO, artigos livres, resenhas, ensaios fotográficos, dossiês (propostas).}

Interessados na submissão de trabalhos e também em atuar como

\section{pareceristas}

podem realizar seus cadastros em

https://periodicoscientificos.ufmt.br/ojs/index.php/aceno 